\title{
Evaluation of a Mathematical Model Based on Lubanska Equation to Predict Particle Size for Close-Coupled Gas Atomization of 316L Stainless Steel
}

\author{
Flávia Costa da Silva ${ }^{a, b *}$ (D), Moysés Leite de Lima ${ }^{b}$ (D), Giovanna Fiocco Colombo ${ }^{b}$ (D) \\ ${ }^{a}$ Universidade de São Paulo, Escola de Engenharia de São Carlos, Av Trabalhador São Carlense, 400, \\ Parque Arnold Schimidt, 13566-590, São Carlos, SP, Brasil. \\ ${ }^{b}$ Instituto de Pesquisas Tecnológicas de São Paulo, Laboratório de Processos Metalúrgicos, \\ Av. Prof. Almeida Prado, 532, Butantã, 05508-901, São Paulo, SP, Brasil.
}

Received: July 15, 2021; Revised: November 24, 2021; Accepted: December 28, 2021

\begin{abstract}
Close-Coupled Gas Atomization (CCGA) is often used to produce spherical metal powders with a wider Particle Size Distribution (PSD) $(10-500 \mu \mathrm{m})$ compared to that required by the main Additive Manufacturing processes $(10-105 \mu \mathrm{m})$. This work presents an accuracy evaluation of a mathematical model based on the Lubanska equation to predict the $\mathrm{d} 50$ for CCGA. Atomization experiments of $316 \mathrm{~L}$ steel were conducted to evaluate the tip diameter and atomization gas pressure effects on PSD and, the $\mathrm{d} 50$ experimental results were used as the reference to the mathematical model evaluation. The mathematical model accuracy could be improved by: (i) considering the backpressure phenomenon for the metal flow rate calculation, since it was an important inaccuracy source; (ii) reviewing the tip diameter effect, which had a lower impact on d50 than that predicted by the Lubanska equation. The atomization gas pressure was the most influential parameter on d50 and d90 and the increase of the gas pressure led to a significant reduction in PSD and, consequently, increased yield.
\end{abstract}

Keywords: close-coupled gas atomization, additive manufacturing, 316L powder, Lubanska equation, process parameters.

\section{Introduction}

Close-Coupled Gas Atomization (CCGA) is often used to produce fine and spherical metal powders, highly needed for Additive Manufacturing (AM) of metallic alloys. Nevertheless, the Particle Size Distribution (PSD) of these powders produced by gas atomization is wide $(10-500 \mu \mathrm{m})^{1}$, and the main AM processes use narrower ranges, for example, $10-45 \mu \mathrm{m}$ for Powder Bed Fusion (PBF) and 45 - $105 \mu \mathrm{m}$ for Direct Energy Deposition (DED). As a consequence, the powder residue rate is between $65 \%{ }^{2}$ to $85 \%{ }^{3}$. Anderson et al. ${ }^{3}$ affirm that, currently, one of the main research objectives in the powder production process for AM is to duplicate the yield in the particle size range $10-105 \mu \mathrm{m}$.

In CCGA with discrete jets, the metallic alloy is melted in a reservoir that contains a tube that guides the metal flow to the atomization chamber, which consists of a melt feed nozzle and a gas die around the melt tip feed. In this chamber, the gas flow (e.g. air, nitrogen or argon) exits through individual jets in a matrix just below the tip of the melt feed nozzle and the gas expands around the melt stream, leading to a strong depressurization and disintegration of the liquid metal. The high-speed gas jet transfers kinetic energy to the metal flow and forms liquid metal droplets, which subsequently solidify to form spherical particles ${ }^{4,5}$. Short distances between the gas exit and melt stream favor energy transfer and, hence, the smaller droplets formation. In this type of nozzle, the volume of gas consumed is small

*e-mail: flavia.costa@outlook.com due to the small gas outlet area, allowing the use of high pressure of atomization gas and better control and refinement of the particle size ${ }^{6-8}$.

The median particle size (d50) given by Lubanska equation is dependent of process variables, such as liquid metal outlet area, gas outlet area, gas pressure, pressure in the fusion chamber and melt superheat. The gas and metal temperature and their chemical compositions influence physicochemical properties (e.g. viscosities, densities and melt surface tension) and, consequently, the particle size, because it determine the heat exchange $\mathrm{e}^{4,9-11}$.

The d50 is also influenced by Gas-Metal Ratio (GMR). Particle size decreases by increasing GMR. The gas mass flow rate $(\dot{G})$ is adjusted by the gas outlet area and the gas pressure. Increasing the gas pressure, the gas kinetic energy is also increased which leads to a higher action distance of the gas on the melt stream, increasing the secondary atomization and, thus, reducing the particle size. The liquid metal mass flow rate $(\dot{M})$ can be adjusted by some process parameters: melt tip diameter, metallostatic pressure and pressurizing the fusion chamber ${ }^{6,12}$. The tip diameter reduction increases the resistance to metal flow and, consequently, the metal flow decreases. The fusion chamber pressure is mainly applied to maintain the metal flow constant and avoid clogging due to the backflow caused by the effect of the backpressure on the tip in close-coupled nozzles.

The backpressure is one of the main causes of the metal flow clogging in the guide tube by pushing the metal in the 
opposite direction to its flow and freezing the metal due to the high speed of the gas at a low temperature near the metal nozzle ${ }^{13,14}$. According to Mates and Settles ${ }^{15}$, the backpressure is formed when the gas jet exits the Convergent-Divergent nozzle (C-D), accelerates and expands reaching supersonic velocity, generating a radial pressure gradient along the metal delivery tip base and forming a gas recirculation zone downstream of the tip. The gas pressure in the centerline, below the tip, also forces the metal to the edges where the gas flow with high kinetic energy reaches the metal and the atomization is more vigorous.

In CCGA, the main influence of GMR is on the width of the particle size distribution curve, given by the Inter Decil Range (IDR) of the cumulative curve ${ }^{16,17}$. The distribution curve can have a larger or smaller width depending on the frequency of oscillation and pulsation movements in the metal jet stream, which is also caused by the effect of the gas in this type of nozzle $\mathrm{e}^{16,18,19}$. Therefore, gas atomization of liquid metal alloys is a process with many variables acting simultaneously that influence the resulting particle size, and it is important to understand the influence of atomization parameters process on the powders properties.

The comprehension of the particle formation process in gas atomization currently can be supported by Computational Fluid Dynamics (CFD) simulation. However, these simulations deal mainly with the study of gas flow, since the simulation of two fluids with different properties such as liquid metal and gas are considered complex ${ }^{20-23}$. Due to the difficulty of associating particle size with atomization parameters, analytical models based mostly on the Lubanska equation or equations derived from it are widely used to evaluate the influence of process variables on particle size, represented by $\mathrm{d} 50^{24-29}$. The Lubanska equation is considered the most popular to predict the $\mathrm{d} 50$ presenting reasonable accuracy under various experimental conditions in gas atomization. Many authors suggest new equations or modifications in the Lubanska equation in order to predict d50 in different types of atomizers. These modified Lubanska equations consider the GMR as an input parameter that is often difficult to calculate because the existing empirical equations for gas and metal mass flows do not consider the phenomena occurring in CCGA. Urionabarrenetxea et al. ${ }^{30}$ affirm that the Kishidaka equation (modified Lubanska equation), which presented four adjustment parameters, is the most accurate for CCGA. However, it is crucial to consider that this equation was developed for water atomization in which backpressure phenomenon does not occur.

This work aims to present an empirical analytical model based on the Lubanska equation, which consists of a set of equations selected from the literature that best fit for a CCGA with discrets jets C-D nozzle. After the application of the model, experiments were applied to verify the model accuracy. In addition, the influence of the process parameters on the particle size distribution was verified by analyzing $\mathrm{d} 10, \mathrm{~d} 50$ and $\mathrm{d} 90$ of the $316 \mathrm{~L}$ atomized powder. Moreover, due to the rising demand for metal alloy powders for AM and the need to increase the yield for the particle size range for AM process such PBF and DED, the yield was evaluated as a function of the parameters.

\section{Materials and Methods}

\subsection{Mathematical model}

The mathematical model evaluated in the present work consists of a set of equations (Table 1) selected from the literature and applied to calculate the median particle size (d50). The equation used to calculate the $\mathrm{d} 50$ was the Lubanska equation $^{31}$ (Equation 1) and is often used because takes into account the main parameters that influence the formation of particles in the gas atomization process and usually can be used for all types of atomizers as a first analytical approach for process evaluation ${ }^{32}$.

The physicochemical properties of the liquid metals in the Lubanska equation are temperature dependent. Equations 2 to 4 also presented in other works ${ }^{33,34}$ to calculate the $316 \mathrm{~L}$ steel properties at high temperature were used to estimate the viscosity $\eta_{\mathrm{m}}\left(\mathrm{m}^{2} / \mathrm{s}\right)$, surface tension $\sigma_{\mathrm{m}}(\mathrm{N} / \mathrm{m})$ and density $\rho_{\mathrm{m}}\left(\mathrm{kg} / \mathrm{m}^{3}\right)$ at the temperature used in the present atomization experiments.

The calculation of the gas jet velocity $\left(\mathrm{U}_{\mathrm{g}}\right)$ is done by applying Equation 5. The gas flow is an isentropic process, which means that the gas velocity is a function of the type of atomizing gas (nitrogen, argon, etc.), its temperature and the atomization pressure. This equation can be used in gas atomization analytical models for convergent-divergent nozzles, and its results were considered as a reference to estimate the gas velocity at the outlet point of the nozzle ${ }^{35}$. It is known that the gas velocity is also a function of the position considering the atomization nozzle as a reference ${ }^{29,36,37}$, but this is not taken into account in Equation 5. Thus, this equation should be considered an estimative for atomization gas velocity and, therefore, it is a limitation of this model.

The liquid metal mass flow $(\dot{M})$ was calculated by Equation $6^{38}$, which is based on Bernoulli equation considering losses due to friction $\varphi$ (Equation 7) and takes into account the metallostatic pressure effect on the metal exit velocity. However, the atomizer used in this work does not allow the automatic control of these parameters and, therefore, the metal mass flow calculation is considered as an estimative.

The gas mass flow ( $\dot{G}$ ) was estimated using Equation $9^{25,39,40}$, which presented a good agreement with the gas consumption mass measured experimentally during the atomization process for the close-coupled nozzle in the present work. It is known that the gas mass flow can be calculated using numerical models. However, in the present work, it is proposed an analytical approach as a useful tool to be applied in the atomization experiments planning and, in its results general analysis.

\subsection{Experimental procedure}

The $316 \mathrm{~L}$ powder was produced by gas atomization in a laboratory-scale atomizer (Phoenix Scientific Industries Ltd, model Hermiga 75/3) using argon as atomizing gas. The gas nozzle was a close-coupled type with 20 holes of $0.4 \mathrm{~mm}$ in diameter of a convergent-divergent discrete jet nozzle. The $316 \mathrm{~L}$ alloy was melted in a ceramic crucible using an induction furnace, and the batches weight were nearly $3 \mathrm{~kg}$. The melt delivery tube was a $2.5 \mathrm{~mm}$ internal diameter alumina tube.

The experiments were planned with the support of a full factorial design of experiments (DoE), initially considering 
Table 1. Proposed mathematical model (set of equations) used to calculate the median particle size d50 based on Lubanska equation.

\begin{tabular}{|c|c|}
\hline \multicolumn{2}{|l|}{$\begin{array}{r}\text { Equations } \\
\end{array}$} \\
\hline 1. $d 50=K \sqrt{\left[\frac{\eta_{m} \sigma_{m} d_{0}}{\eta_{g} U_{g}^{2} \rho_{m}}\left(1+\frac{\dot{M}}{\dot{G}}\right)\right]}$ & \multirow{10}{*}{$\begin{array}{l}\mathrm{d} 50=\text { median particle size }(\mu \mathrm{m}) \\
\mathrm{K}=\text { a constant that depends on the type of atomizer } \\
\eta_{\mathrm{m}}=\text { kinematic viscosity of the metal }\left(\mathrm{m}^{2} / \mathrm{s}\right) \\
v_{\mathrm{m}}=\text { dynamic viscosity }\left(\mathrm{N} \cdot \mathrm{s} / \mathrm{m}^{2}\right) \\
\rho_{\mathrm{m}}=\text { density of the metal }\left(\mathrm{kg} / \mathrm{m}^{3}\right) \\
\rho_{\mathrm{g}}=\text { density of the gas }\left(\mathrm{kg} / \mathrm{m}^{3}\right) \\
\eta_{\mathrm{g}}=\text { kinematic viscosity of the gas }\left(\mathrm{m}^{2} / \mathrm{s}\right) \\
\sigma_{\mathrm{m}}=\text { surface tension of the metal }(\mathrm{N} / \mathrm{m}) \\
\mathrm{T}=\text { temperature of the metal }(\mathrm{K}) \\
\mathrm{d}_{0}=\text { tip diameter }(\mathrm{m}) \\
\mathrm{U}_{\mathrm{g}}=\text { gas velocity }(\mathrm{m} / \mathrm{s}) \\
\mathrm{R}^{2}=\text { constant of the gases }\left(8.314 \mathrm{~m}^{3} . \mathrm{Pa} / \mathrm{K} \cdot \mathrm{mol}\right) \\
\mathrm{M}=\text { molar mass of the gas }(\mathrm{kg} / \mathrm{mol}) \\
\mathrm{k}=\text { coefficient of heat capacities at constants pressure and volume of } \\
\mathrm{a} \text { gas Cp/Cv } \\
\mathrm{P}_{1}=\text { atomization pressure }(\mathrm{Pa}) \\
\mathrm{P}_{2}=\text { atmospheric pressure in the atomization chamber }(\mathrm{Pa}) \\
\mathrm{T}_{1}=\text { gas temperature inside the nozzle }(298.15 \mathrm{~K}) \\
\mathrm{P}_{\mathrm{g}}=\text { gas pressure }(\text { bar }) \\
\dot{M}=\text { metal flow }(\mathrm{kg} / \mathrm{s}) \\
\varphi=\text { coefficient of friction } \\
\mathrm{A}_{0}=\text { tip area }\left(\mathrm{m}^{2}\right) \\
\mathrm{P}_{\mathrm{f}}=\text { pressure in the fusion chamber }(\mathrm{bar}) \\
\mathrm{g}=\text { gravity acceleration }\left(\mathrm{m} / \mathrm{s}^{2}\right) \\
\mathrm{h}_{\mathrm{m}}=\text { height of liquid metal }(\mathrm{m}) \\
\mathrm{Re}=\text { Reynolds number } \\
\mathrm{V}_{\mathrm{m}}=\text { exit velocity of the metal }(\mathrm{m} / \mathrm{s}) \\
\dot{G}=\text { gas flow }(\mathrm{kg} / \mathrm{s}) \\
\mathrm{A}_{\mathrm{g}}=\text { gas exit area }\left(\mathrm{m}^{2}\right) \\
\end{array}$} \\
\hline 2. $\eta_{m}=\frac{v_{m}}{\rho_{m}} ; \ln v_{m}=(-2.396+7950 / T)$ & \\
\hline 3. $\sigma_{m}=1840-0.4(T-1823)$ & \\
\hline $\begin{array}{l}\quad \rho_{m}=(69.4 \% \mathrm{Fe})+(66.3 \% \mathrm{Cr})+(71.4 \% \mathrm{Ni})+ \\
\text { 4. }(57.2 \% \mathrm{Mn})+(51.5 \% \mathrm{Mo})+(49.3 \% \mathrm{Si})- \\
\quad 0.86(\mathrm{~T}-1823)\end{array}$ & \\
\hline 5. $U_{g}=\sqrt{\frac{R \cdot T_{1}}{M} \cdot \frac{2 \cdot k}{k-1} \cdot\left[1-\left(\frac{P_{2}}{P_{1}}\right)\right]^{\frac{k-1}{k}}}$ & \\
\hline 6. $\dot{M}=\varphi A_{0} \rho_{m} \sqrt{2\left[\frac{P_{f}}{\rho_{m}}+g h_{m}\right]}$ & \\
\hline 7. $\varphi=1-\frac{7.96}{\sqrt{\operatorname{Re}}}$ & \\
\hline 8. $R e=\frac{\rho_{m} V_{m} d_{0}}{\mu_{m}}$ & \\
\hline 9. $\dot{G}=A_{g} \sqrt{\left(k \rho_{g} P_{g}\right)\left[\frac{2}{k+1}\right]^{\left(k+\left(\frac{1}{k}\right)-1\right)}}$ & \\
\hline 10. $\rho_{g}=4.5\left(1.6317 * 10^{-6} P_{g}+1.0585\right)$ & \\
\hline
\end{tabular}

3 levels and 5 parameters: atomization gas pressure, fusion chamber pressure, tip outlet diameter, liquid metal height and superheat temperature. The first round of DoE analysis indicated an expressive number of experiments. To reduce the number of experiments, a statistical analysis calculated by the relative standard deviation was performed considering each level and calculated the mean, standard deviation and mean standard error of the d50 values. This made it possible to obtain in percentage the degree of influence of each parameter in the $\mathrm{d} 50$ from the mathematical model. Liquid metal height and superheat temperature were the parameters with less influence and then, were fixed at constants values, allowing to reduce the number of experiments. The liquid metal height $\left(\mathrm{h}_{\mathrm{m}}\right)$ was fixed at $90 \mathrm{~mm}$, and the superheat temperature $\left(\mathrm{T}_{\mathrm{s}}\right)$ was set at $200 \mathrm{~K}$ leading to a casting temperature of $1913 \mathrm{~K}$. This temperature is close to the limit of ceramic crucible material, and it was chosen to avoid clogging by freezing the metal at the tip. Moreover, the fusion chamber pressure $\left(\mathrm{P}_{\mathrm{f}}\right)$ choice aimed to guarantee the continuous liquid metal flow and avoid clogging due to the backpressure effect. Setting these parameters, the factorial design was reduced to 3 levels for each of the 2 parameters: tip outlet diameter $\left(\mathrm{d}_{0}\right)$ and atomization gas pressure $\left(\mathrm{P}_{\mathrm{g}}\right)$. Table 2 presents all
Table 2. Parameters used in gas atomization of $316 \mathrm{~L}$ alloy experiments and applied in the $\mathrm{d} 50$ calculation by the mathematical model.

\begin{tabular}{|c|c|c|c|c|c|}
\hline Experiment Code & $\mathrm{P}_{\mathrm{g}}$ (bar) & $\mathrm{d}_{0}(\mathrm{~mm})$ & $\begin{array}{c}\mathrm{P}_{\mathrm{f}} \\
\text { (bar) }\end{array}$ & $\mathrm{h}_{\mathrm{m}}(\mathrm{mm})$ & $\begin{array}{c}\mathrm{T}_{\mathrm{s}} \\
(\mathrm{K})\end{array}$ \\
\hline A & 30 & \multirow{3}{*}{1.5} & \multirow{6}{*}{0.3} & \multirow{9}{*}{90} & \multirow{9}{*}{200} \\
\hline $\mathrm{B}$ & 40 & & & & \\
\hline $\mathrm{C}$ & 50 & & & & \\
\hline $\mathrm{D}$ & 30 & \multirow{3}{*}{2.0} & & & \\
\hline $\mathrm{E}$ & 40 & & & & \\
\hline $\mathrm{F}$ & 50 & & & & \\
\hline $\mathrm{G}$ & 30 & \multirow{3}{*}{2.5} & \multirow{2}{*}{0.2} & & \\
\hline $\mathrm{H}$ & 40 & & & & \\
\hline I & 50 & & 0.3 & & \\
\hline
\end{tabular}

experimental conditions and the experiment identification. In summary, the experimental conditions are:

- $\quad$ Atomization gas pressure ( $\mathrm{P}_{\mathrm{g}}: 30,40$ and 50 bar);

- $\quad$ Fusion chamber pressure ( $\left(\mathrm{P}_{\mathrm{f}}: 0.2\right.$ and 0.3 bar);

- $\quad$ Tip outlet diameter $\left(\mathrm{d}_{0}: 1.5,2.0\right.$ and $\left.2.5 \mathrm{~mm}\right)$;

- Liquid metal height in the fusion chamber $\left(\mathrm{h}_{\mathrm{m}}: 90 \mathrm{~mm}\right)$;

- $\quad$ Superheat temperature $\left(\mathrm{T}_{\mathrm{s}}: 200 \mathrm{~K}\right)$. 
The powder obtained in each atomization experiment was sieved according to ASTM B214, using a mechanical vibrator for 20 minutes and a sieve set with the following meshes: 18 , 20, 30, 40, 50, 70, 100, 140, 200, 230, 325, 635 and 1250 . With the sieving procedure, it was possible to plot the particle size distribution curves. From the distribution curves, it was possible to calculate the percentiles d10, d50 and d90 from which it was calculated the IDR of the distribution curves $(I D R=d 90-d 10)$. Considering the particle size range for PBF $(10-45 \mu \mathrm{m})$ and DED $(45-105 \mu \mathrm{m})$, the yields were calculated ( $\% \mathrm{wt})$ for each AM process for all experiments.

In addition, the $316 \mathrm{~L}$ powders from those experiments that presented the highest yield were characterized regarding the particle shape and morphology considering the range for PBF and DED using two techniques: Scanning Electron Microscopy (SEM) and Dynamic Image Analysis (DIA). The DIA results made it possible to quantify shape aspects such as Circularity and Feret Aspect Ratio, which is complemented by SEM analysis that provides information about morphology and surface quality of the particles, including the satellites.

\subsection{Mathematical model analysis}

The accuracy of the mathematical model (Table 1) was evaluated by comparing the $\mathrm{d} 50$ values calculated by mathematical model and that obtained from the distribution curves generated from the sieving of the $316 \mathrm{~L}$ atomized powder obtained with the parameters conditions presented in Table 2. The accuracy of the mathematical model was evaluated through the $\mathrm{R}^{2}$ (coefficient of determination), mean and mean absolute errors. The $\mathrm{R}^{2}$ was calculated using linear regression of the plotted data comparing the $\mathrm{d} 50$ values from the mathematical model and from the experiments.

The analysis of variance (ANOVA) was used to evaluate whether the difference between the results from the mathematical model and experiments are significant, as well as to analyze the parameters influence on the $\mathrm{d} 50$. The P-value and F-statistic were used as indicators and the model was considered inaccurate for a P-value lower than 0.05 .

Moreover, the $\mathrm{d} 50$ values obtained using the mathematical model and the experimental results were evaluated as a function of GMR. The GMR was calculated using values for metal mass flow rates and the gas mass flow rates calculated using equations 6 and 9 (Table 1), respectively. In the experimental GMR the experimental metal flow rate $\left(\dot{M}_{\text {exp }}\right)$ was obtained by the ratio between the weight of the metal and the total atomization time. Consequently, the experimental metal flow rate is not an instantaneous measurement, but an average flow rate. The experimental gas flow rate was determined by Equation 9, because of the agreement with previous experiments, as mentioned.

\section{Results and Discussions}

\subsection{Mathematical model evaluation}

The Lubanska equation (Equation 1) includes an adjustable parameter that is a constant $(\mathrm{K})$. The value of parameter $\mathrm{K}$ obtained in this study was 180 , which is different from reported by Lubanska $(\mathrm{K}=40-80)^{31,38}$. This parameter depends on the type of atomizer and Lubanska has determined this value using a free-fall atomizer that, therefore, could explain this difference between the $\mathrm{K}$ values. Other works showed that higher values were necessary $(K=123-162)^{25,30}$ in order to adapt to modern models of gas atomizers, considering that this constant incorporates not only the characteristics of the type of atomizer but the properties of the liquid metal ${ }^{28}$ and the gas pressure applied ${ }^{41}$.

The $\mathrm{d} 50$ calculated by the model based on the Lubanska equation (Table 1) was compared to the experimental d50 in Figure 1. The data labels represent the gas pressure and tip diameter of each experiment. The accuracy of the mathematical model was evaluated by the $\mathrm{R}^{2}$ from a linear regression and the P-values and F-statistic were used as indicators. In Figure 1 the dotted line represents the ideal fit line where the $\mathrm{d} 50$ calculated by the model would be equal to the experimental d50. Large dispersion of the values was observed in the graphic and confirmed by the low $\mathrm{R}^{2}(0.05)$. The Lubanska and experimental d50 values and their respective errors were shown in Table 3 . The mathematical model presents a mean error of $9 \mu \mathrm{m}$, and a mean absolute

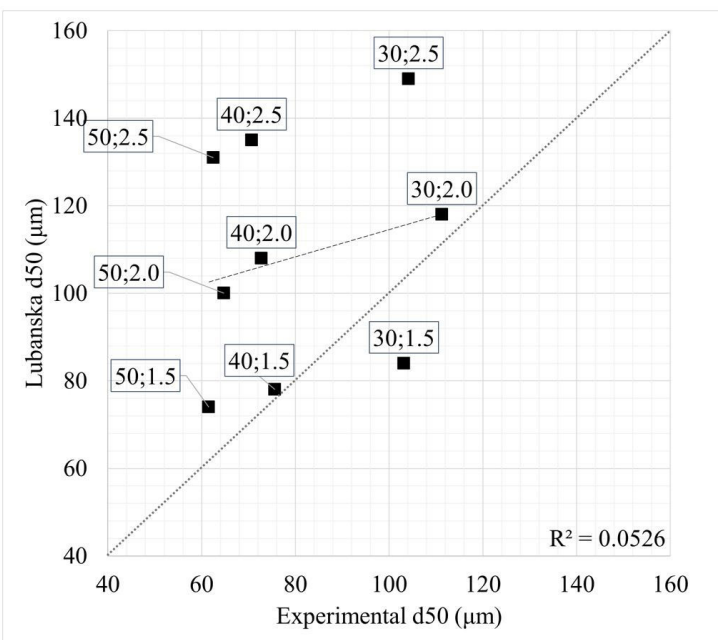

Figure 1. Experimental v.s. Lubanska d50 values. The data labels represent the gas pressure and tip diameter of each experiment.

Table 3. Lubanska and experimental d50 values with their mean and mean absolute error.

\begin{tabular}{cccc}
\hline $\begin{array}{c}\text { Experiment } \\
\text { Code }\end{array}$ & $\begin{array}{c}\text { Lubanska } \\
(\mu \mathrm{m})\end{array}$ & $\begin{array}{c}\text { Lubanska } \\
\text { with } \dot{M} \text { exp } \\
(\mu \mathrm{m})\end{array}$ & $\begin{array}{c}\text { Experimental } \\
(\mu \mathrm{m})\end{array}$ \\
\hline $\mathrm{A}$ & 84 & 85 & 103 \\
\hline $\mathrm{B}$ & 78 & 72 & 76 \\
\hline $\mathrm{C}$ & 74 & 59 & 62 \\
\hline $\mathrm{D}$ & 118 & 102 & 111 \\
\hline $\mathrm{E}$ & 108 & 77 & 73 \\
\hline $\mathrm{F}$ & 100 & 70 & 65 \\
\hline $\mathrm{G}$ & 149 & 110 & 104 \\
\hline $\mathrm{H}$ & 135 & 77 & 71 \\
\hline $\mathrm{I}$ & 131 & 80 & 63 \\
\hline $\begin{array}{c}\text { Mean Error } \\
(\mu \mathrm{m})\end{array}$ & 9.0 & 5.3 & 6.6 \\
\hline $\begin{array}{c}\text { Mean } \\
\text { Absolute } \\
\text { Error }(\mu \mathrm{m})\end{array}$ & 68 & 18 & - \\
\hline
\end{tabular}


error up to $68 \mu \mathrm{m}$ was observed between calculated and measured values. The mathematical model inaccuracy was confirmed by the analysis of variance results obtained by ANOVA. The low P-value (0.02) and high F-statistic (6.28) showed that the difference between the d50 calculated by the mathematical model and the experimental d50 obtained from the distribution curves are statistically significant.

Investigating the discrepancy between d50 values calculated using the mathematical model based on the Lubanska equation and experimental values, it was identified that the metal flow rate calculated by Equation 6 differs significantly from that observed in the experiments. This can be observed in the data presented in Table 4, which presents the calculated metal flow rate by the mathematical model $\left(\dot{M}_{c a l}\right)$ and the experimental metal flow rate calculated by the ratio of atomized metal mass and atomization time ( $\left.\dot{M}_{\text {exp }}\right)$. The Equation 6 of the mathematical model suggests that the metal flow depends on the tip diameter, as show in Figure 2, i.e. the metal flow increases with the tip diameter. For the atomizer used in the present work, the metal flow values obtained experimentally indicate that the metal flow depends on tip diameter, but the gas atomization pressure and fusion chamber pressure also have a significant influence.

The general behavior observed for all tip diameters is that by increasing the atomization gas pressure the experimental metal flow rate decreases. There is only one exception that is the experiments $\mathrm{H}\left(P_{g}=40 \mathrm{bar}\right)$ and I $\left(P_{g}=50 \mathrm{bar}\right)$. However, experiment $\mathrm{H}$ used 0.2 bar on the fusion chamber while experiment I used 0.3 bar and, thus, the metal flow rate increased for the experiment I.

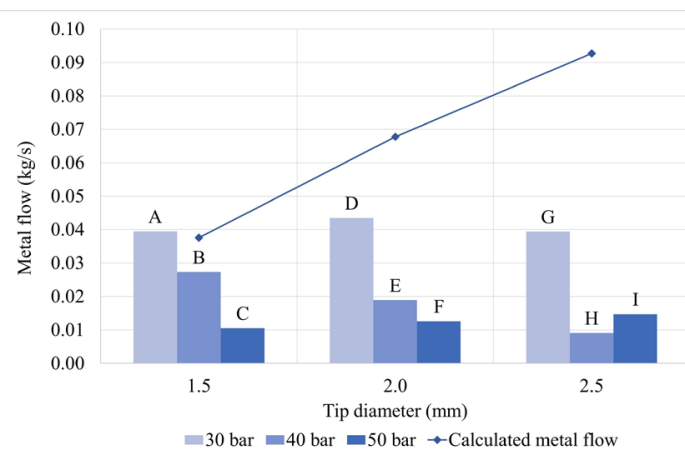

Figure 2. Influence of the tip diameter and gas pressure on the experimental and calculated metal flow.
Equation 6 does not consider oscillations in metal flow rate caused by the proximity of the gas to the metal nozzle in close-coupled type atomizers. This equation proved to be more adequate for free-fall type atomizers in which the metal flow is not affected by the gas. It is well established in the literature that the backpressure phenomenon is common in close-coupled nozzles, and it is related to the gas atomization pressure, however, information about backpressure equation are limited ${ }^{14,15,19,21,38,42}$. In CCGA with discrete jets, there is a gas recirculation zone or wake downstream of the metal nozzle tip, which generates a stagnation point near the melt exit hole. This stagnation point generates a backpressure in the descendent melt flow. The wake can oscillate, opening and closing, increasing and decreasing the metal flow, respectively, which makes it difficult to control the metal flow in close-coupled atomizers, and it is one of the explanations for the wide PSD obtained in this type of atomizer ${ }^{7,16,43}$

The analysis of variance results obtained by ANOVA for the influence of the parameters on the experimental metal flow rate showed that the tip diameter has low influence on the experimental metal flow, the high P-value (0.93) and low F-statistic (0.08) indicate that the variation of the tip diameter does slightly alter the metal flow rate and there is another factor influencing it. Indeed, the metal flow is strongly affected by the gas pressure, as can be seen in the experimental results presented in Figure 2, confirmed by the low P-value (0.001) and high F-statistic (21.48).

In order to verify the mathematical model accuracy, the metal flow rate calculated by Equation 6 was replaced in the model by the values of metal flow obtained experimentally (Lubanska with $\dot{M}_{\text {exp }}$ ). The mathematical model based on Lubanska equation has its accuracy increased, as can be seen in Figure 3, by the approximation of the data to the dotted adjustment line and the higher $\mathrm{R}^{2}=0.729$. Besides that, the mean and the mean absolute error were reduced to $5.3 \mu \mathrm{m}$ and $18 \mu \mathrm{m}$, respectively. These errors values were lower than those presented by Urionabarrenetxea et al. ${ }^{30}$ for the Lubanska equation (mean error $=9 \mu \mathrm{m}$ and mean absolute error $=43 \mu \mathrm{m})$ and are similar to the Kishidaka equation (mean error $=4 \mu \mathrm{m}$ and mean absolute error: $18 \mu \mathrm{m}$ ), which considers four adjusted parameters and was more accurate in predicting the $\mathrm{d} 50$ in their work. In addition, the P-value (0.96) and F-statistic (0.003) confirm the accuracy of the mathematical model. The high P-value indicates that the d50 calculated by the mathematical model modified by the experimental metal flow is not statistically different from the experimental $\mathrm{d} 50$.

Table 4. Calculated and experimental metal flow rate for each experiment.

\begin{tabular}{cccccc}
\hline Experiment Code & $\mathrm{P}_{\mathrm{g}}(\mathrm{bar})$ & $\mathrm{d}_{0}(\mathrm{~mm})$ & $\mathrm{P}_{\mathrm{f}}(\mathrm{bar})$ & $\dot{M}_{\text {cal }}\left(10^{-3} \mathrm{~kg} / \mathrm{s}\right)$ & $\dot{M}_{\text {exp }}\left(10^{-3} \mathrm{~kg} / \mathrm{s}\right)$ \\
\hline $\mathrm{A}$ & 30 & 1.5 & 0.3 & 37.5 & 39.5 \\
\hline $\mathrm{B}$ & 40 & 1.5 & 0.3 & 37.5 & 27.3 \\
\hline $\mathrm{C}$ & 50 & 1.5 & 0.3 & 67.7 & 10.5 \\
\hline $\mathrm{D}$ & 30 & 2.0 & 0.3 & 67.7 & 18.5 \\
\hline $\mathrm{E}$ & 40 & 2.0 & 0.3 & 67.7 & 12.6 \\
\hline $\mathrm{F}$ & 50 & 2.0 & 0.3 & 92.7 & 39.4 \\
\hline $\mathrm{G}$ & 30 & 2.5 & 0.2 & 92.7 & 9.1 \\
\hline $\mathrm{H}$ & 40 & 2.5 & 0.2 & 106.3 & 14.7 \\
\hline $\mathrm{I}$ & 50 & 2.5 & 0.3 & & \\
\hline
\end{tabular}




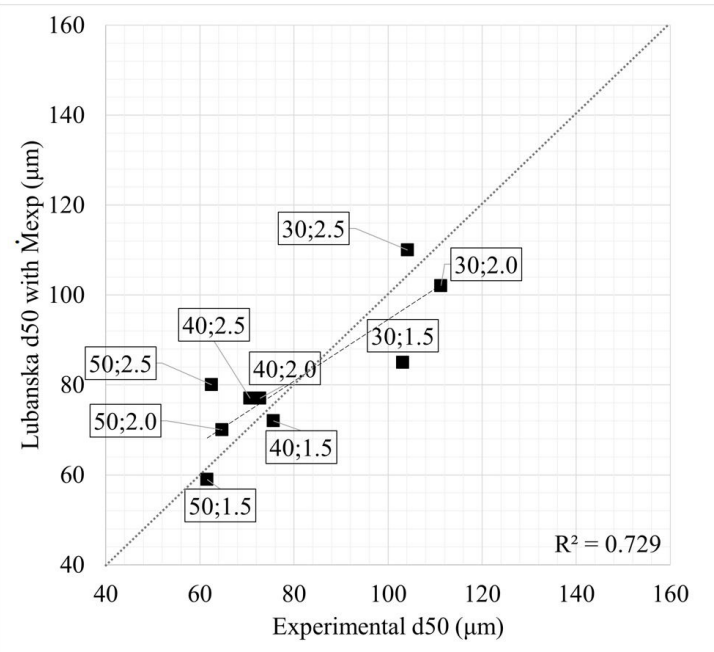

Figure 3. Experimental v.s. Lubanska d50 values with experimental metal flow. The data labels represent the gas pressure and tip diameter of each experiment.

Another way to evaluate the accuracy of the mathematical model to predict the $\mathrm{d} 50$ is by analyzing this parameter as a function of gas-metal ratio (GMR), as presented in Figure 4. It is clear in the data presented in Figure 4 that there is a significant difference between the data obtained experimentally and those predicted by the mathematical model. When experimental metal flow rate data are used in the model (Lubanska with $\dot{M}_{\text {exp }}$ ), the mathematical model results are closer to the experimental. This evaluation corroborates the analysis of the metal flow rate presented previously indicating an important effect of the backpressure on the metal flow rate and in the $\mathrm{d} 50$.

From the evaluation of these results, it was verified that a modification in the equation for the metal flow rate is necessary to increase the accuracy of the mathematical model to predict the median particle size. An equation for metal flow rate calculation should consider the backpressure effect acting in the opposite direction to the metal flow and, thus, the metal flow rate would be a function of the gas pressure as well as another parameter.

\subsection{Process parameters influence on $d 50$}

The present analysis intends to identify the most influential parameter in the median particle size by evaluating the percentage of individual influence of each atomization process parameters on $\mathrm{d} 50$. This statistical analysis was conducted using DoE tool in MatLab software and the results are shown in Figure 5, which compares the parameters influence on d50 calculated by the mathematical model (Lubanska), the d50 calculated by the mathematical model modified with the experimental metal flow (Lubanska with $\dot{M}_{\text {exp }}$ ) and the d50 measured experimentally (Experimental).

The first analysis was performed on the mathematical model (Lubanska) using the parameters in Table 2. The relative standard deviation of the process parameters indicated a low influence of the liquid metal height $\left(\mathrm{h}_{\mathrm{m}}=0.7 \%\right)$ and fusion chamber pressure $\left(\mathrm{P}_{\mathrm{f}}=4.6 \%\right)$ when compared to the superheat temperature $\left(\mathrm{T}_{\mathrm{s}}=8.5 \%\right)$, atomization gas pressure $\left(\mathrm{P}_{\mathrm{g}}=8.3 \%\right)$

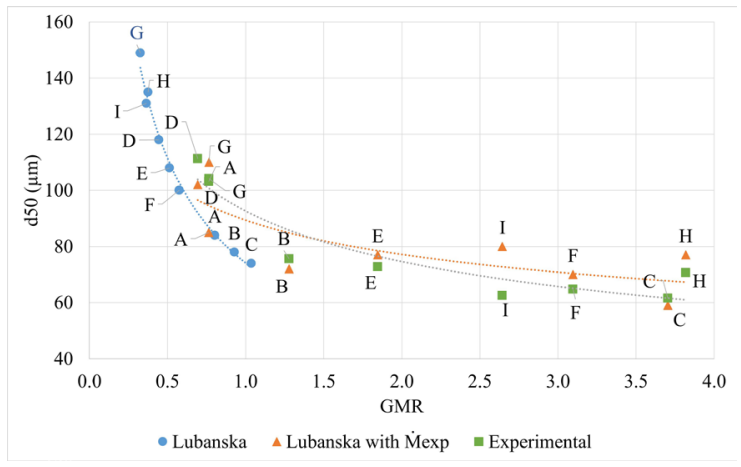

Figure 4. d50 versus GMR.

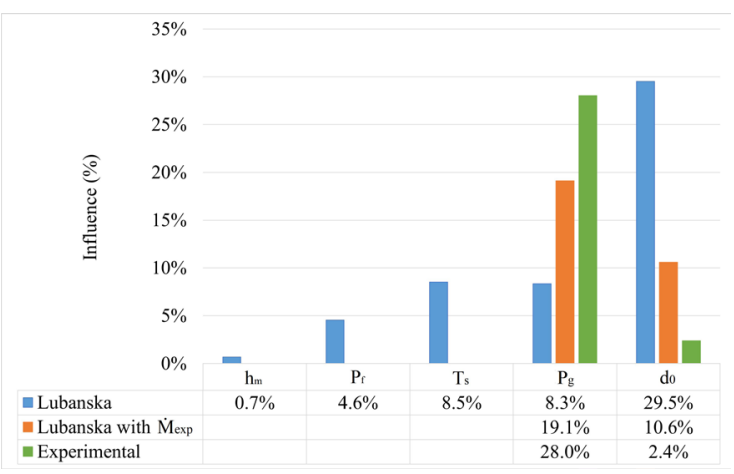

Figure 5. Parameters influence in the median particle size d50.

and tip diameter $\left(d_{0}=29.5 \%\right)$. Hence, as mentioned in the experimental procedure, three parameters $\left(\mathrm{h}_{\mathrm{m}}, \mathrm{P}_{\mathrm{f}}\right.$ and $\left.\mathrm{T}_{\mathrm{s}}\right)$ are taken as constants for the experiments and for the other two statistical analyses of the most influential parameter on $\mathrm{d} 50$. For the mathematical model modified with the experimental metal flow (Lubanska with $\dot{M}_{\text {exp }}$ ) the gas pressure would be the most important parameter (19\%), and the tip diameter still would have a significant influence $(10 \%)$ on the $\mathrm{d} 50$.

For the parameters influence evaluated from the experimental $\mathrm{d} 50$, the atomization gas pressure was the most influential parameter $(28 \%)$, while the tip diameter had a low influence $(2.4 \%)$ on the $\mathrm{d} 50$. These results are in agreement with what is established in the literature for close-coupled atomization ${ }^{8,38,44}$ and are similar to the results presented by Pariona et al. ${ }^{45}$ who used the fractional factorial method to determine the effects of the main parameters and identified that the gas pressure has the most significant effect on the $\mathrm{d} 50$, followed by the opening area of the gas nozzle and tip diameter.

A different way to analyze the influence of the parameters comparing the mathematical model and the experimental results is presented in Figure 6 that presents the median particle size (d50) as a function of atomization gas pressure (Figure 6a) and as a function of tip diameter (Figure 6b). Once more, the experimental results show clearly that the atomization gas pressure had a greater impact on reducing the particle size than the tip diameter. Moreover, the variation of the experimental d50 results was less affected above 30 bar, as seen in Figure 6a, indicating that possibly from this point, the used nozzle system is getting closer to its limit capacity to reduce the d50 with increasing the gas atomization pressure. 


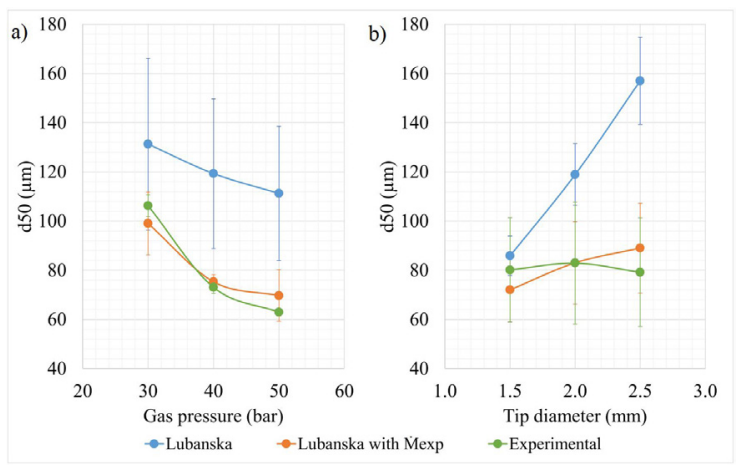

Figure 6. Median particle size calculated using the mathematical model, calculated with the experimental metal flow rate and experimental $\mathrm{d} 50$ as a function of the a) gas pressure and b) tip diameter.

Considering the $\mathrm{d} 50$ as a function of atomization gas pressure (Figure 6a) the analysis of variance results resulted a low P-values (0.00 and 0.02) and high F-statistic (161.97 and 7.73) for the experimental and calculated (Lubanska with $\dot{M}_{\text {exp }}$ ) d50, indicating a d50 statistically different when the gas pressure was altered, mainly for the experimental results. On the other hand, when the mathematical model (Lubanska) was used to calculate the d50, a higher P-value (0.82) and a lower F-statistic $(0.21)$ were obtained from the statistical analysis indicating no significant difference between the d50 when the gas pressure varies from 30, 40 and 50 bar.

The mathematical model results showed an important influence of tip diameter on d50 (Figure 6b) confirmed by low P-value (0.00) and high F-statistic (39.90) what disagrees with the experimental results. However, as discussed in item 3.1, this conflict between the mathematical model and experimental results can be partially related to the backpressure effect on the metal nozzle tip, that has a major influence on the metal flow rate neglected by the model. Without the backpressure phenomenon, the metal flow would increase with tip diameter increasing and, as a result, the Lubanska d50 would increase, as seen in Figure 6b. However, in the experimental results, it can be considered that there was no statistical difference of d50 as a function of tip diameter (P-value was 0.98 and F-statistic was 0.02) and, therefore, it can be stated that there is no significant influence of this parameter on the d50 (standard deviation was $2.4 \%$ ). Figure $6 \mathrm{~b}$ shows that increasing the tip diameter increases the $\mathrm{d} 50$ (calculated with experimental metal flow in the mathematical model Lubanska with $\dot{M}_{\exp }$ ), but less intense than indicated by the original model (Lubanska), confirmed by the P-value ( 0.47$)$ and F-statistic (0.85), representing more accuracy than the original model (Lubanska).

Baram et al. ${ }^{18}$ indicated that the tip diameter does not affect the $\mathrm{d} 50$ because the change in tip diameter is not enough to change the metal flow rate. The present work experimental results show that the metal flow rate was influenced by the tip diameter, but these changes did not affect the $\mathrm{d} 50$ results significantly. The comparison between experiments B, E and H (Figure 2) is an example of this result. The experimental results of the present work indicate that the effect of atomization gas pressure prevails on the d50 over the tip diameter. Therefore, as it was identified that the tip diameter has a low influence on the $\mathrm{d} 50$, for future works its effect should be revised within the Lubanska equation to reduce its impact on the calculated d50 and increase the equation accuracy for discrete jet CCGA.

\subsection{Process parameters effect on the particle size distribution}

Since the tip diameter presented low influence on the median particle size, the following discussion will focus on the atomization gas effect. In this regard, the production of fine particles was due to two possible reasons reported in fluid dynamic studies ${ }^{46,47}: 1$ ) reduction of metal flow rate due to backpressure generated by overexpanded atomization gas, causing an increase in GMR and 2) the expansion waves transfer more kinetic energy to the metal, favoring the break of the droplets. These two effects taking place simultaneously are present above 30 bar, and, above this pressure, the nozzle system is more effective to reduce the particle size. There was a reduction of about $30 \%$ on the $\mathrm{d} 50$ with atomization gas pressure increasing from 30 to 40 bar observed in the experimental results (Figure 6a and Table 3). However, the effect of gas pressure on experimental d50 was not constant and, above 40 bar the nozzle starts to reduce its ability to decrease $\mathrm{d} 50$ (when the gas pressure increases from 40 to 50 bar the d50 decreases 14\%).

The particle size reduction can be seen in Figure 7, which shows the deciles d90, d50 and d10 as a function of GMR. As expected, it was observed a particle size decrease for all deciles increasing the GMR, and the reduction of $\mathrm{d} 90$ was the most noticeable. The more intense reduction on $\mathrm{d} 90$ decile led to narrow distribution increasing GMR, as can be seen in Figure 8. Higher GMR values contributed to obtaining finer powders and to narrow particle size distributions, in which finer particles were produced by reducing the coarse particles size.

The results presented in Figure 7 are an evidence that considering the $\mathrm{d} 50$ value as a reference for the analysis of atomization process parameters effect should be revisited. In some cases, changing process parameters will result in similar d50 values, but significantly different values of d90 and, thus, different distributions. Therefore, a mathematical model for $\mathrm{d} 90$ prediction would be useful to analyze the atomization processes parameters effects on the particle size distribution.

Regarding the process parameters evaluated, the particle size reduction represented mainly by the $\mathrm{d} 90$ was caused by increasing the gas pressure. Figure 9 presents the average IDR of the experiments for each atomizing gas pressure and shows that increasing the gas pressure, a significant reduction in the IDR was observed, which is evidence of the influence of this parameter. The reduction of the IDR and the increase of finer particles were caused by the two effects mentioned above: 1) the reduction of the liquid metal flow, caused by the effect of backpressure, and 2) the increase in the kinetic energy of the gas, which allows the secondary atomization to be more intense.

The general analyses presented above indicates that the GMR is a result of simultaneous changes in the gas flow $(\dot{G})$ and in the metal flow $(\dot{M})$ rates. The increase in the atomization gas pressure leads to an increase in $\dot{G}$ and, at the same time, it reduces $\dot{M}$ due to the backpressure effect. However, the 


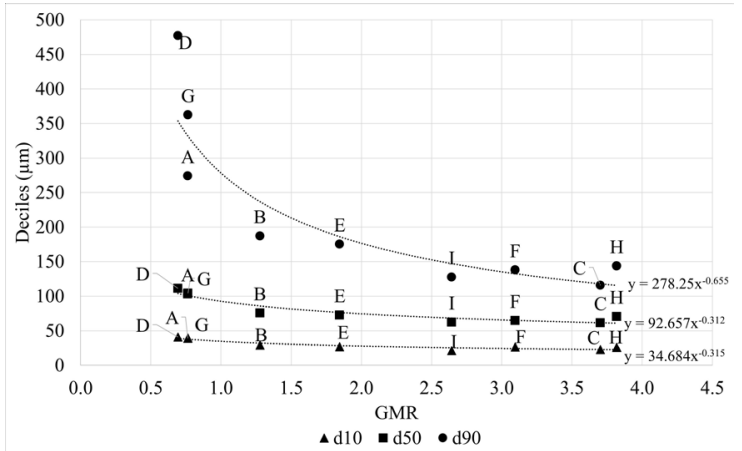

Figure 7. Deciles (d90, d50 and d10) as a function of GMR.

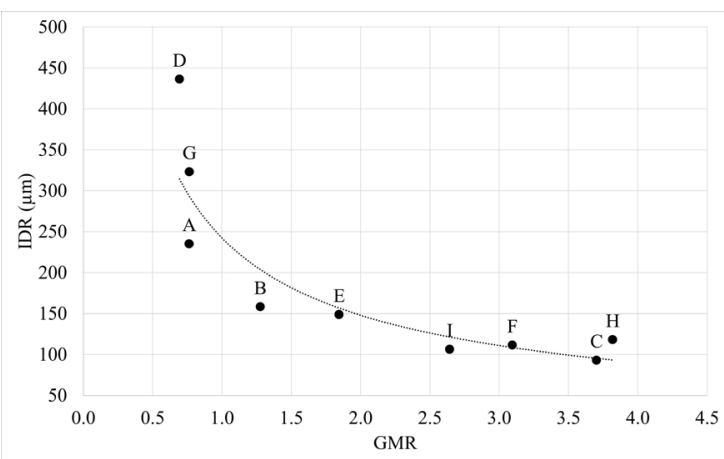

Figure 8. IDR as a function of GMR.

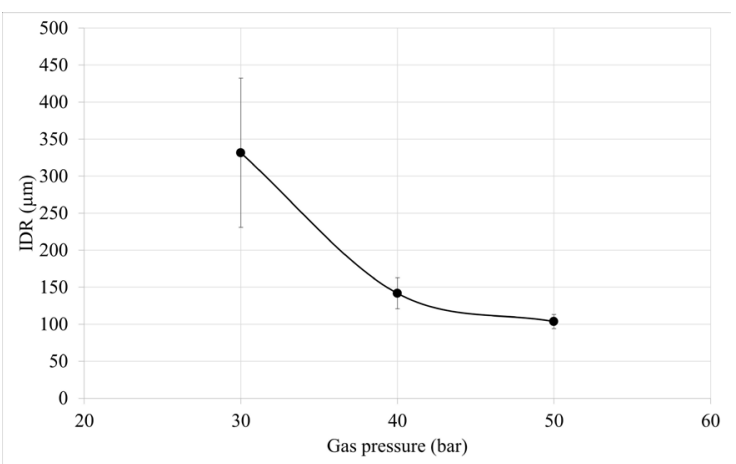

Figure 9. Atomization gas pressure influence on the Inter Decile Range (IDR).

fusion chamber pressure is a process parameter that can be used to change the flow rate of the metal: by decreasing the fusion chamber pressure, the metal flow rate is reduced. This effect can be observed comparing the experiments $\mathrm{H}$ and $\mathrm{I}$. For experiment $\mathrm{H}$ the metal flow rate is lower $\left(9.1 \times 10^{-3} \mathrm{~kg} /\right.$ s) than that measured for I $\left(14.7 \times 10^{-3} \mathrm{~kg} / \mathrm{s}\right)$, resulting in a GMR higher for experiment $\mathrm{H}$, even with a lower atomization gas pressure for the experiment $\mathrm{H}$ (40 bar) compared to the I (50 bar). However, even with a higher GMR, the particle size (d90, d50 and d10) was higher for the experiment $\mathrm{H}$ compared to I. This analysis shows that larger GMR is not always synonymous of finer particles, as observed by other authors ${ }^{17,48}$.

This can be seen by comparing the experimental deciles and IDR for the same GMR $(\mathrm{GMR}=5.13)$ from $316 \mathrm{~L}$ experiments performed by Urionabarrenetxea et al. ${ }^{30}$ on the same atomizer model. To estimate the values of deciles for the same GMR, the trendlines equations in Figure 7 were used. For $\mathrm{x}=5.13$ was obtained $\mathrm{d} 10=20, \mathrm{~d} 50=56$ and $\mathrm{d} 90=95$. This estimated particle size was larger than obtained by others authors ${ }^{30}(\mathrm{~d} 10=7, \mathrm{~d} 50=33$ and $\mathrm{d} 90=$ 83 ) in its atomization experiment. It is important to note that the authors obtained a GMR $=5.13$ using $P_{g}=60$ bar and $\mathrm{T}_{\mathrm{S}}=260 \mathrm{~K}$ (higher than that used in the present work). This confirms that the predominant parameter to determine the reduction of $\mathrm{d} 50$ is the effect of the transfer of kinetic energy from the atomizing gas to the metal flow ${ }^{17}$. Moreover, higher superheat of the liquid metal indicates smaller particle size, attributed to the changes in metal properties ${ }^{12}$.

\subsection{Powder yield for AM processes}

As presented in the previous item, the main influence of GMR is on the width of the distribution. Once it is possible to control the atomization process parameters to obtain low IDR, it is feasible to produce high powder yields within a specific range, in the present case, the range for AM (10-105 $\mu \mathrm{m})$. In Figure 10 the powder yield for each experiment was plotted as a function of GMR. As expected, the highest yield within the specific particle size range (10 to $105 \mu \mathrm{m}$ ) was $87 \%$ for experiment $\mathrm{C}$ (higher atomization gas pressure and smaller tip diameter). The yield was above $80 \%$ for atomization gas pressure of 50 bar (experiments C, F and I). The yield results are in accordance with the deciles results which indicate that the most significant effect of atomization gas pressure was on the $\mathrm{d} 90$ results, reducing the IDR (Figure 9) of the particle size distribution. The yield reduces to $66 \%$ and $72 \%$ when the gas pressure decreases to 40 bar, but an alternative to increase the particle yield was to decrease the fusion chamber pressure from 0.3 bar to 0.2 bar (increasing GMR) represented by the experiment $\mathrm{H}(78 \%)$.

The powder production for AM by gas atomization usually requires a fraction separation from the total powder in a specific range of particle size depending on the AM process and equipment requirements. In this work, the powder was fractionated aiming at the two most common processes in AM for metallic alloys: Direct Energy Deposition (DED), which requires powders within the range of 45-105 $\mu \mathrm{m}$, and Powder Bed Fusion (PBF), which requires powders with particle size between 10-45 $\mu \mathrm{m}$. Figure 11 shows the gas atomization yield accounted for the particle sizes range required to DED and $\mathrm{PBF}$ as a function of the gas pressure.

For all experiments, the powder produced showed a higher yield for the DED process. About $50 \%$ wt $( \pm 10)$ of all powder collected after each experiment presented particle size within the range for DED process, while $20 \%$ wt $( \pm 8)$ of the powder was suitable for use in PBF process.

The gas pressure increasing has a major influence on the atomization yield for both ranges, increasing it for PBF from 12 to $28 \%$ wt, and for DED from 39 to $59 \%$ wt. As mentioned in the literature ${ }^{2,3}$, the gas atomization process for AM has a high rate of powder residues generation, and the main technological goal for this process is to duplicate the yield, which today is around $15 \%$ wt for each size range. According to the results presented in this work, the best efficiency of the process was achieved by applying 50 bar of gas pressure with $1.5 \mathrm{~mm}$ of tip diameter, which corresponded to $13 \% \mathrm{wt}$ of residues. 


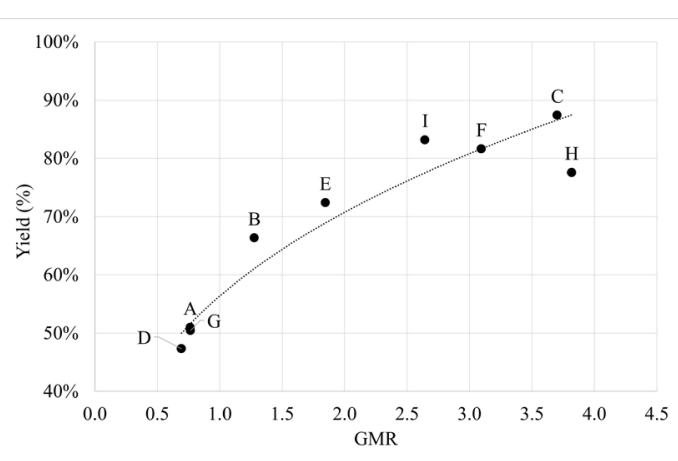

Figure 10. Yield in the range of $10-105 \mu \mathrm{m}$ as a function of GMR.

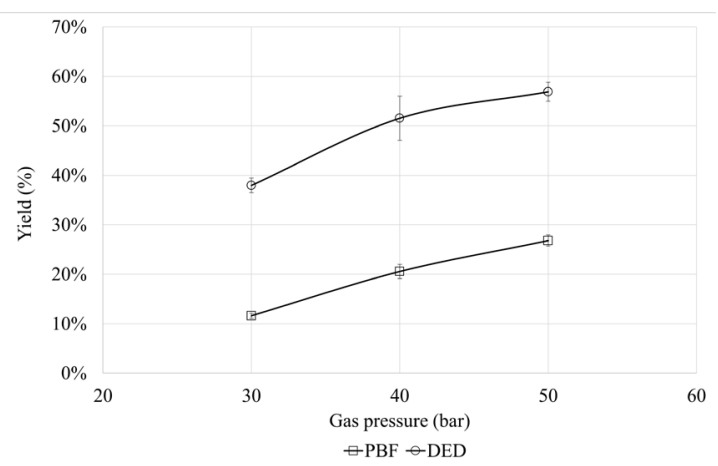

Figure 11. Powder yield accounted for the particle sizes ranges required for DED and PBF processes as a function of gas pressure.

\subsection{Powder morphology}

Powders produced by gas atomization present spherical particle morphology. Some satellites are usually observed attached to the surface of coarse particles. Spherical powders without irregular particles and satellites are required for PBF process, but this requirement does not prevail for $\mathrm{DED}^{3}$. Figure 12 displays micrographs of PBF and DED size fractions separated by sieving. It was observed that the particles of the finest fractions have a predominantly smooth surface, and they are essentially free of surface defects. The spherical shape can be analyzed using the Feret aspect ratio. Feret aspect ratio closer to 1 indicates a particle more round, smooth and equiaxial and, consequently, the inter-particle motion is easier, providing better powder packing ability and rheology performance. For the powder with particle size range measured for PBF, Feret aspect ratio is close to 1 , which is recommended for PBF applications. However, the particles of the coarsest fractions used in DED present a few fine particles aggregates and accretionary particles (indicated in the Figure 12b). The Feret aspect ratio data was similar to the finer fraction, but the circularity was lower, that is coherent with the more irregular and satellites on their surface visible for DED particles compared to the PBF.

The formation of satellites occurs when small particles adhere to the surfaces of larger ones due to collisions during atomization. The tendency to form satellites and aggregates increases with the superheat. The large particles need more time to solidify, so the probability of colliding with the fine particles dragged by the internal recirculation

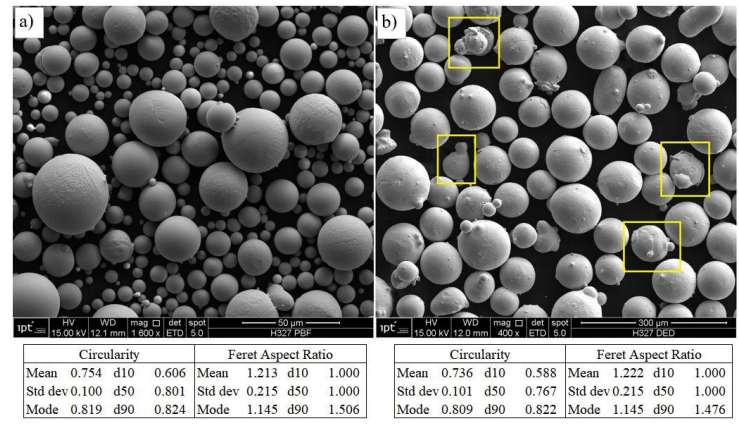

Figure 12. Powder morphology of sample C produced at 50 bar of gas pressure and $1.5 \mathrm{~mm}$ of tip diameter of a) PBF $(10-45 \mu \mathrm{m})$ and b) DED (45-105 $\mu \mathrm{m})$ range.

loops is enhanced ${ }^{49-51}$. The solution to this would be to use a superheat below $200 \mathrm{~K}$.

As the powders were produced in a laboratory atomization chamber, the number of satellites is smaller than that seen in the literature for powders produced in industrial atomizers with larger atomization chambers ${ }^{3,12,30}$.

\section{Conclusions}

In this work, the applicability and accuracy of a mathematical model based on the Lubanska equation was analyzed to predict the median particle size (d50). A modification in the equation for the metal flow is necessary and must consider the backpressure phenomenon to increase the accuracy of the proposed model.

The analysis of the most influential parameter in the particle size showed that the atomization gas pressure had a greater impact on reducing the particle size than the tip diameter $\left(\mathrm{P}_{\mathrm{g}}=28 \%\right.$ and $\left.\mathrm{d}_{0}=2.4 \%\right)$. Since the tip diameter was less influential on the $\mathrm{d} 50$, this factor should be revised within the Lubanska equation to reduce its impact on the prediction of the $\mathrm{d} 50$ and increase the accuracy of the equation.

As the $\mathrm{d} 90$ is much more affected by changing the parameters, the $\mathrm{d} 50$ should be revisited as a reference for the analysis of the atomization process parameter effect. Therefore, a mathematical model for $\mathrm{d} 90$ prediction would be useful for the analysis of atomization processes parameters effects on the particle size distribution.

The powder produced in the experiments showed higher yield (59\%) for the DED range ( $45-105 \mu \mathrm{m})$. The gas pressure had a greater influence on both ranges increasing the yield for PBF from 12 to $28 \% \mathrm{wt}$, and for DED from 39 to $59 \% \mathrm{wt}$ when the applied gas pressure was from 30 bar to 50 bar.

The fine fraction of the powder from experiment $\mathrm{C}$ had a predominantly smooth surface and are practically free of surface defects. The spherical shape was attested by circularity and Feret aspect ratio measurements, which are recommended for PBF applications, facilitating interparticle motion to provide better powder packing ability and rheology performance for the powder bed processes. The coarser particle fraction powder used in DED presented aggregates and accretionary particles. The circularity was lower, more irregular and satellites on their surface were visible. To elucidate if these defects are a problem in the 
processing of these powders in DED, a rheological study of these powders is needed.

\section{Acknowledgments}

The author FCS acknowledges funding by the BCO under grant number 2019/13715-4, São Paulo Research Foundation (FAPESP).

\section{References}

1. Kassym K, Perveen A. Atomization processes of metal powders for 3D printing. Mater Today Proc. 2020;26:1727-33. https:// www.doi.org/10.1016/j.matpr.2020.02.364.

2. Mullis A. The physical mechanism for melt pulsation during close-cloped atomization. At Sprays. 2019;29:143-59.

3. Anderson IE, White EMH, Dehoff R. Feedstock powder processing research needs for additive manufacturing development. Curr Opin Solid State Mater Sci. 2018;22:8-15.

4. Nasr GG, Yule AJ, Bendig L. Industrial sprays and atomization. London: Springer; 2002. https://www.doi.org/10.1007/978-14471-3816-7.

5. Lefebvre AH. Atomization. A-to-Z Guid to Thermodyn. Heat Mass Transf Fluids Eng [serial on the Internet]. $2011 \mathrm{Feb}$ [cited 2021 Dec 28]. Available from: http://dx.doi.org/10.1615/ atoz.a.atomization.

6. Li X, Zhu Q, Shu S, Fan J, Zhang S. Fine spherical powder production during gas atomization of pressurized melts through melt nozzles with a small inner diameter. Powder Technol. 2019;356:759-68.

7. Henein H, Uhlenwinkel V, Fritsching U, editors. Metal sprays and spray deposition. Cham: Springer International Publishing; 2017). http://dx.doi.org/10.1007/978-3-319-52689-8.

8. Gjesing R, Hattel J, Fritsching U. Coupled atomization and spray modelling in the spray forming process using open foam. Eng Appl Comput Fluid Mech. 2009;3:471-86.

9. Zeoli, N. Multiphase modelling of the characteristics of close coupled gas atomization coupled gas atomization [PHD thesis]. Birmingham: Aston University; 2011.

10. Neikov OD. Atomization and granulation. In: Neřkov OD, Naboychenko S, Yefimov NV, editors. Handbook of non-ferrous metal powders. Amsterdam: Elsevier; 2019. p. 125-85. http:// dx.doi.org/10.1016/B978-0-08-100543-9.00004-X.

11. Zheng B, Lavernia EJ. Melt atomization. In: Ashgriz N, editor Handbook of atomization and sprays. New York: Springer; 2011. p. 837-48. http://dx.doi.org/10.1007/978-1-4419-7264-4_36.

12. Ouyang H, Chen X, Huang B. Influence of melt superheat on breakup process of close-coupled gas atomization. Trans Nonferrous Met Soc China. 2007;17:967-73.

13. Motaman S, Mullis AM, Cochrane RF, McCarthy IN, Borman DJ. Numerical and experimental modelling of back stream flow during close-coupled gas atomization. Comput Fluids. 2013;88:1-10.

14. Mi J, Figliola RS, Anderson IE. A numerical investigation of gas flow effects on high-pressure gas atomization due to melt tip geometry variation. Metall Mater Trans, B, Process Metall Mater Proc Sci. 1997;28:935-41.

15. Mates SP, Settles GS. A study of liquid metal atomization using close-coupled nozzles, part 2: atomization behavior. At Sprays. 2005;15:41-59.

16. Mullis AM, McCarthy IN, Cochrane RF. High speed imaging of the flow during close-coupled gas atomisation: effect of melt delivery nozzle geometry. J Mater Process Technol. 2011;211:1471-7.

17. Anderson IE, Achelis L. Two fluid atomization fundamentals. In: Henein H, Uhlenwinkel V, Fritsching U, editors. Metal sprays and spray deposition. Cham: Springer; 2017. p. 49-88. http://dx.doi.org/10.1007/978-3-319-52689-8_3.

18. Baram JC, Veistinen MK, Lavernia EJ, Abinante M, Grant NJ. Pressure build-up at the metal delivery tube orifice in ultrasonic gas atomization. J Mater Sci. 1988;23:2457-63.

19. Mates SP, Settles GS. A study of liquid metal atomization using close-clouped nozzles, part 1: gas dynamic behavior. At Sprays. 2005; 15:19-40.

20. Zeoli N, Tabbara H, Gu S. CFD modeling of primary breakup during metal powder atomization. Chem Eng Sci. 2011;66:6498504.

21. Ting J, Anderson IE. A computational fluid dynamics (CFD) investigation of the wake closure phenomenon. Mater Sci Eng A. 2004;379:264-76.

22. Aydin O, Unal R. Experimental and numerical modeling of the gas atomization nozzle for gas flow behavior. Comput Fluids. 2011;42:37-43.

23. Beckers D, Ellendt N, Fritsching U, Uhlenwinkel V. Impact of process flow conditions on particle morphology in metal powder production via gas atomization. Adv Powder Technol. 2020;31:300-11.

24. Bergmann D, Fritsching U, Bauckhage K. A mathematical model for cooling and rapid solidification of molten metal droplets. Int J Therm Sci. 2000;39:53-62.

25. Gutierrez-Miravete E, Lavernia EJ, Trapaga GM, Szekely J, Grant NJ. A mathematical model of the spray deposition process. Metall Trans, A, Phys Metall Mater Sci. 1989;20:71-85.

26. Pariona MM, Bolfarini C, dos Santos RJ, Kiminami CS. Application of mathematical simulation and factorial design method to the optimization of the atomization stage in the spray forming of a $\mathrm{Cu}-6 \% \mathrm{Zn}$ alloy. J Mater Process Technol. 2000;102:221-9.

27. Sobolev VV, Guilemany JM, Martin AJ. Formation of powder particles during thermal interaction of liquid and solidified drops in the process of metal atomization. J Mater Process Technol. 1996;62:216-24.

28. Quested PN, Brooks RF, Day AP, Richardson MJ, Mills KC. Physical properties of alloys relevant to spray forming. Powder Metall. 1997;40:131-4.

29. León GP, Lamberti VE, Seals RD, Abu-Lebdeh TM, Hamoush SA. Gas atomization of molten metal: Part I. Numerical modeling conception. Am J Eng Appl Sci. 2016;9:303-22.

30. Urionabarrenetxea E, Avello A, Rivas A, Martín JM. Experimental study of the influence of operational and geometric variables on the powders produced by close-coupled gas atomisation. Mater Des. 2021;199:109441.

31. Lubanska H. Correlation of spray ring data for gas atomization of liquid metals. JOM. 1970;22:45-9.

32. Antipas GSE. Review of gas atomisation and spray forming phenomenology. Powder Metall. 2013;56:317-30.

33. Mills KC, Yuchu SU, Zushu LI, Brooks RF. Equations for the calculation of the thermo-physical properties of stainless steel. ISIJ Int. 2004;44:1661-8.

34. Su Y, Li Z, Mills KC. Equation to estimate the surface tensions of stainless steels. J Mater Sci. 2005;40:2201-5.

35. Liu, G. How to select and start up a fluidized-bed jet mill system. Powderbulk. 2016;(June):1-5.

36. Kaiser R, Li C, Yang S, Lee D. A numerical simulation study of the path-resolved breakup behaviors of molten metal in high-pressure gas atomization: with emphasis on the role of shock waves in the gas/molten metal interaction. Adv Powder Technol. 2018;29:623-30.

37. Thompson JS, Hassan O, Rolland SA, Sienz J. The identification of an accurate simulation approach to predict the effect of operational parameters on the particle size distribution (PSD) of powders produced by an industrial close-coupled gas atomiser. Powder Technol. 2016;291:75-85. 
38. Fritsching U. Spray simulation: modelling and numerical simulation of sprayforming metals.Cambridge: Cambridge University Press; 2004.

39. Pariona M, Bolfarini C, Kiminami CS. Atomization stage analysis of liquid dynamic compaction process by fractional factorial design. Zeitschrift für Met. 1998;7:494-7.

40. Singh D, Koria SC, Dube RK. Velocity of gas from free fall type atomisers. Powder Metall. 1999;42:79-85.

41. Metz R, Machado C, Houabes M, Pansiot J, Elkhatib M, Puyanē R, et al. Nitrogen spray atomization of molten tin metal: powder morphology characteristics. J Mater Process Technol. 2007;189:132-7.

42. Fritsching U, Bauckhage K. Spray forming of metals. In: Ullmann F, Bohnet M, editors. Ullmann's encyclopedia of industrial chemistry. Weinheim: Wiley; 2006. http://dx.doi. org/10.1002/14356007.b24_b02.pub2.

43. Zerwas AA, Avila K, de Paiva JL, Guardani R, Achelis L, Fritsching U. Image analysis of the atomization process in a molten metal close-coupled atomizer for different gas pressures and temperatures. In: 15th Triennial International Conference on Liquid Atomization and Spray Systems; 2021 Aug 29-Sept 2; Edinburgh. Proceedings. Edinburgh: ICLASS; 2021.

44. Ünal R. Improvements to close coupled gas atomisation nozzle for fine powder production. Powder Metall. 2007;50:66-71.
45. Pariona MM, Bolfarini C, Kiminami CS. Atomization stage analysis of liquid dynamic compaction process by fractional factorial design. Int J Mater Reser. 1998;89:494-7.

46. Xu Q, Cheng D, Trapaga G, Yang N, Lavernia EJ. Numerical analyses of fluid dynamics of an atomization configuration. $\mathrm{J}$ Mater Res. 2002;17:156-66.

47. Ünal A. Influence of gas flow on performance of "Confined" atomization nozzles. Metall Trans, B, Process Metall. 1989;20:833-43.

48. Mullis AM, Cochrane RF, McCarthy IN, Adkins NJ. Log-normal melt pulsation in close-coupled gas atomization. Metall Mater Trans, B, Process Metall Mater Proc Sci. 2013;44:789-93.

49. Achelis L, Uhlenwinkel V. Characterisation of metal powders generated by a pressure-gas-atomiser. Mater Sci Eng A. 2008;477:15-20.

50. Urionabarrenetxea E, Martín JM, Rivas A, Iturriza I, Castro F. Experimental study and simulation of the gas flow in the atomisation chamber during close-coupled gas atomisation. In: European PM Conference Proceedings. 2013 Sept 15-18. Gothenburg, Sweden. Shrewsbury: The European Powder Metallurgy Association; 2013. p. 1-7.

51. Schwenck D, Ellendt N, Mädler L, Fischer-Bühner J, Hofmann $\mathrm{P}$, Uhlenwinkel V. Generation of small batch high quality metal powder. Powder Metall. 2014;57:171-5. 